\title{
Fitoextração de cobre e zinco de um Neossolo Quartzarênico contaminado com metais pesados
}

\author{
Lucia Helena Garófalo Chaves*, Ramara Sena de Souza
}

Universidade Federal de Campina Grande, Campina Grande, PB, Brasil

*Autor correspondente, e-mail: Ingarofalo@hotmail.com

\begin{abstract}
Resumo
O uso de plantas para fitorremediação do solo constitui uma técnica capaz de empregar sistemas vegetais fotossintetizantes a fim de diminuir o nível de metais presentes nele. Objetivou-se com este trabalho avaliar a capacidade de extração de metais pesados por plantas de pinhão-manso (Jatropha curcas L), cultivadas sob um Neossolo Quartzarênico. O experimento foi realizado em cassa de vegetação, utilizando-se vasos com capacidade para $8,6 \mathrm{~kg}$. O delineamento experimental foi inteiramente casualizado, com três repetições, sendo cinco níveis de cobre 10 ; 20; 40; 60 e $\left.80 \mathrm{mg} \mathrm{dm}^{-3}\right)$ e cinco níveis de zinco $\left(0 ; 20 ; 40 ; 60\right.$ e $\left.80 \mathrm{mg} \mathrm{dm}^{-3}\right)$. A colheita das plantas foi feita aos 90 dias após a semeadura sendo determinados: produção de matéria seca, os metais pesados nas plantas e os teores de tais metais no solo. A aplicação dos metais cobre e zinco diminuiu a matéria seca total das plantas e aumentou suas concentrações em todas as partes da planta. O pinhão-manso é mais eficiente em extrair zinco em relação ao cobre sendo por isso, necessário um maior número de cultivos em solos contaminados com o cobre.
\end{abstract}

Palavras-chave: contaminação, Jatropha curcas L., remediação

\section{Phytoextraction of copper and zinc from an entisol contaminated with heavy metals}

\begin{abstract}
The use of plants for soil phytoremediation is a technique capable of using photosynthetic plant systems to reduce levels of soil metals. The objective of this study was to evaluate the ability of extracting heavy metals by Jatropha (Jatropha curcas L) plants, grown under an entisol. The experiment was carried out in a greenhouse, using pots with $8.6 \mathrm{~kg}$ of capacity. The experimental design was completely randomized with three replications, with five levels of copper $(0,20,40,60$ and $\left.80 \mathrm{mgdm}^{-3}\right)$ and five levels of zinc $\left(0,20,40,60\right.$ and $\left.80 \mathrm{mgdm}^{-3}\right)$. Plant was harvested 90 days after sowing and the dry matter content, plant and soil heavy metals content were evaluated. With the application of copper and zinc, plant total dry matter decreased and the concentrations of these evaluated metals increased in all plant parts. The Jatropha is more efficient in extracting zinc than copper, which is a demand of a greater number of crops grown in copper contaminated soils.
\end{abstract}

Key words: contamination, remediation, Jatropha curcas 


\section{Introdução}

Os ecossistemas terrestres, como solos, com elevada concentração de metais pesados, exigem ação remediadora que diminua os teores desses polventes em níveis ambientalmente seguros (Tavares et al., 2013). Essa ação, pelas atividades humanas, pode ser feita através de vários métodos, tais como escavação, incineração e outros que são bastante dispendiosos. Por isso, em anos recentes passou-se a dar preferência por métodos "in situ" que perturbem menos o ambiente e sejam mais econômicos. Dentro deste contexto, a biotecnologia oferece a fitorremediação a qual pode ser conceituada como o uso de plantas e sua microbiota associada com o fim de desintoxicar ambientes degradados ou polvídos. É uma técnica não destrutiva, com baixo custo (Tandy et al., 2004), remediando vários contaminantes ao mesmo tempo (Lambert et al., 2012). Entretanto, uma das desvantagens da fitorremediação é a lentidão na obtenção dos resultados por causa do crescimento das espécies que dependem da estação, do clima, solo, além do fornecimento de água.

Um tipo de fitorremediação utilizado é a fitoextração, que envolve a absorção pelas raízes, nas quais os contaminantes são armazenados ou são transportados e acumulados nas partes aéreas. As plantas hiperacumuladoras são altamente especializadas em acumular ou tolerar altíssimas concentrações de metais (Raskin et al., 1994). No Brasil, ainda são poucos os trabalhos relacionados a este assunto e a maioria deles é considerada como trabalhos acadêmicos (Santos et al., 2007; Coscione \& Berton, 2009; Gabos et al., 2009)

As peculiaridades do pinhão-manso fizeram com que surgisse nos últimos tempos, esse interesse em utilizá-lo na produção de biodiesel e na fitorremediação de solos contaminados por metais pesados por esta espécie não ser utilizada na alimentação humana (Chaves et al., 2010).

Dentre os metais pesados, temse o cobre e o zinco. O cobre é um dos micronutrientes essenciais para o crescimento da planta. Ele está envolvido em inúmeras funções fisiológicas como um componente de várias enzimas (Hansch \& Mendel, 2009).
No entanto, quantidades excessivas de cobre torna-se tóxico, uma vez que interfere com processos fotossintéticos e respiratórios, na síntese de proteínas e o desenvolvimento de organelas vegetais (Upadhyay \& Panda, 2009). Especificamente, o excesso de cobre pode provocar clorose, inibição de crescimento da raiz e danos para a permeabilidade da membrana plasmática (Bouazizi et al. , 2010).

O zinco participa de muitas enzimas com papel, principalmente, de catalisador e em muitas funções celulares, tais como - metabolismo de proteínas, de carbono fotossintético e do ácido indol acético, entretanto, com maiores concentrações causam toxicidade (Sinhal, 2007). A deficiência de Zn afeta o crescimento dos caules e das raízes e os sintomas de toxicidade de Zn nas plantas, em geral, são semelhantes aos de deficiência do elemento. Um dos principais mecanismos de toxicidade de $\mathrm{Zn}$ pode ser um aumento da permeabilidade das membranas radiculares, o que fará com que os nutrientes saiam a partir das raízes (Kabata - Pendias \& Pendias, 1992).

O objetivo desse trabalho foi avaliar - comportamento do pinhão-manso na fitorremediação de solo contaminado por metais pesados como cobre e zinco.

\section{Material e Métodos}

O experimento foi realizado em casa de vegetação pertencente à Unidade Acadêmica de Engenharia Agrícola da Universidade Federal de Campina Grande, no período de julho a outubro de 2011, utilizando-se vasos plásticos com $10 \mathrm{~L}$ de capacidade os quais foram preenchidos com $8,60 \mathrm{~kg}$ de substrato, constituído por solo franco arenoso classificado como Neossolo Quartzarenico (Embrapa, 2006), coletado na camada superficial do solo 10 $0,20 \mathrm{~m}$ de profundidade), tendo como atributos químicos: $\mathrm{pH}\left(\mathrm{H}_{2} \mathrm{O}\right)=5,4 ; \mathrm{Ca}=1,08 \mathrm{cmol}_{\mathrm{c}} \mathrm{kg}^{-1}$; $\mathrm{Mg}=0,82 \mathrm{cmol}_{\mathrm{C}} \mathrm{kg}^{-1} ; \mathrm{Na}=0,07 \mathrm{cmol}_{\mathrm{C}} \mathrm{kg}^{-1} ; \mathrm{K}=0,18$ $\mathrm{cmol}_{\mathrm{c}} \cdot \mathrm{kg}^{-1} ; \mathrm{H}=3,85 \mathrm{cmol}_{\mathrm{c}} \mathrm{kg}^{-1} ; \mathrm{Al}=0,2 \mathrm{cmol}_{\mathrm{c}} \mathrm{kg}^{-1}$; matéria orgânica $=4,8 \mathrm{~g} \mathrm{~kg}^{-1} ; \mathrm{P}=4,6 \mathrm{mg} \mathrm{kg}^{-1}$.

$\mathrm{O}$ experimento foi instalado em delineamento inteiramente casualizado, com três repetições, sendo com cinco doses de Cu e Zn (0; 20; 40; 60 e $80 \mathrm{mg} \mathrm{dm}^{-3}$ ) perfazendo o total 
de trinta unidades experimentais, ou seja, quinze unidades experimentais com $\mathrm{Cu}$ e nos outros quinze com Zn, utilizando-se como fontes dos elementos sulfato de cobre e sulfato de zinco.

O substrato foi incubado com os metais Cu e Zn, por um período de 25 dias, mantido com umidade a $50 \%$ de sua capacidade máxima de retenção de água. Após este período foi aplicado em cada unidade experimental adubação com uréia (1,91 g de nitrogênio por unidade experimental), com superfosfato triplo (5,61 $\mathrm{g}$ de $\mathrm{P}_{2} \mathrm{O}_{5}$ por unidade experimental) e com cloreto de potássio $\left(2,08 \mathrm{~g}\right.$ de $\mathrm{K}_{2} \mathrm{O}$ por unidade experimental). A adubação fosfatada foi aplicada toda em fundação e as adubações potássica e nitrogenada foram distribuídas da seguinte forma: $1 / 2$ das quantidades de potássio e de nitrogênio foram aplicadas aos 28 dias após a semeadura (DAS), e o restante foram aplicadas a 52 DAS.

Cada unidade experimental recebeu cinco sementes de pinhão-manso, tendo permanecido após o primeiro e o segundo desbaste, realizados vinte dias e trinta dias após o semeio (DAS), duas e uma planta por unidade, respectivamente.

Durante todo o período experimental (90 dias), o solo foi mantido com umidade corresponde a $80 \%$ da capacidade de campo, tendo sido monitorada diariamente pelo método de pesagens.

Ao final do experimento, após 90 DAS, as plantas foram colhidas, sendo o material vegetal separado em raízes, caules e folhas, o qual, depois de lavado em água destilada e seco em estufa de circulação forçada de ar a $70^{\circ} \mathrm{C}$, até peso constante, foi pesado e moído em moinho tipo Wiley. Posteriormente, efetuou-se a digestão nitroperclórica do material para determinação, nos extratos, de Cu e Zn por espectrofotometria de absorção atômica. Os teores destes elementos presentes nos substratos também foram determinados por espectrofotometria de absorção atômica.

O acúmulo (A) do Cu e do Zn nas folhas, caules e raízes das plantas (mg) foi calculado pela expressão, $\mathrm{A}=\frac{\text { MSC ou MSF ou MSR }(\mathrm{mg}) \times \text { Concentração do elemento }\left(\mathrm{mg} \mathrm{kg}^{-1}\right)}{1000}$ onde:

MSC-massa seca dos caules;

MSF-massa seca das folhas;

MSR-massa seca das raízes.

A quantidade total de $\mathrm{Cu}$ e de $\mathrm{Zn}$ acumulada na planta foi calculada pelo somatório das quantidades acumuladas deste elemento em cada parte da planta.

$\mathrm{NC}=\frac{\text { Teor de metal aplicado no solo de cada vaso }}{\text { Teor de metal acumulado na parte aérea de cada planta }}$

O número de cultivos necessários para descontaminar a amostra de solo do vaso foi calculado da seguinte forma .

A matéria seca total produzida (MST) foi obtida pela equação MST = MSP x NC; onde MSP-matéria seca produzida e NC-número de cultivos necessários para descontaminar a área (Zeitouni et al., 2007).

Os dados foram analisados através da análise de variância e análise de regressão, através do programa estatístico software SISVAR 5.3. (Ferreira, 2009).

\section{Resultados e Discussão}

A aplicação de cobre e de zinco no solo provocou alterações nas reações fisiológicas das plantas de pinhão-manso influenciando, de forma significativa, a fitomassa seca das plantas (Tabela 1), ou seja, em geral a fitomassa seca diminuiu em função do aumento das doses dos elementos aplicados ao solo (Figuras 1 e 2).

Este comportamento foi observado também por Marques et al. (2000) que constataram que a produção de matéria seca da parte aérea das espécies arbóreas estudadas foi influenciada pela contaminação do solo (Zn, $\mathrm{Cd}, \mathrm{Pb}$ e $\mathrm{Cu})$, onde algumas espécies tiveram seu crescimento comprometido, como a Hymenaea courbarile Mimosa caesalpiniaefolia Benth. Da mesma forma foi constatado por Zeitouni et al. (2007) que a aplicação de zinco ao solo, diminuiu a matéria seca de várias culturas, como girassol, tabaco, mamona e pimenta. Entretanto, Chaves et al. (2011) não verificaram diferença significativa na produção de massa seca da parte aérea de girassol cultivado com doses crescentes de cobre e zinco, ou seja, com 0; 20; 40; 60 e $80 \mathrm{mg} \mathrm{dm}^{-3}$. 
Tabela 1. Resumo das análises de variância da fitomassa seca de caule, de folha, de raiz e fitomassa seca total das plantas de pinhão-manso em função das doses de cobre e do zinco

\begin{tabular}{|c|c|c|c|c|c|}
\hline \multirow{3}{*}{ Fonte de Variação } & \multirow{3}{*}{$G L$} & \multicolumn{4}{|c|}{ Quadrado médio } \\
\hline & & \multicolumn{4}{|c|}{ Fitomassa Seca } \\
\hline & & Caule & Folha & Raiz & Total \\
\hline \multicolumn{6}{|l|}{ Cobre } \\
\hline Tratamentos & 4 & $36,33^{* *}$ & $17,52 \mathrm{~ns}$ & $9,25^{* *}$ & $164,36 \mathrm{~ns}$ \\
\hline Resíduos & 10 & 3,38 & 6,50 & 1,17 & 21,64 \\
\hline CV\% & & 40,43 & 56,04 & 31,57 & 37,15 \\
\hline \multicolumn{6}{|l|}{ Zinco } \\
\hline Tratamentos & 4 & $34.29^{* *}$ & $13.04^{* *}$ & $9.02 * *$ & $154.60^{* *}$ \\
\hline Resíduos & 10 & 2.55 & 1.35 & 0.79 & 11.58 \\
\hline CV \% & & 32.39 & 27.36 & 25.55 & 26.88 \\
\hline
\end{tabular}

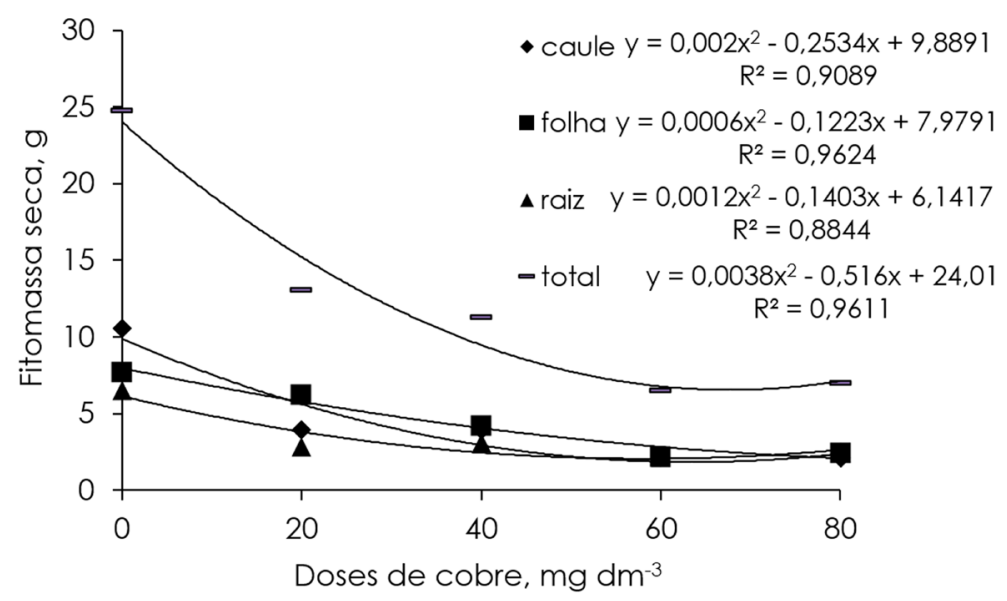

Figura 1. Fitomassa seca de caule, de folha, de raiz e fitomassa seca total das plantas de pinhão-manso em função das doses do cobre.

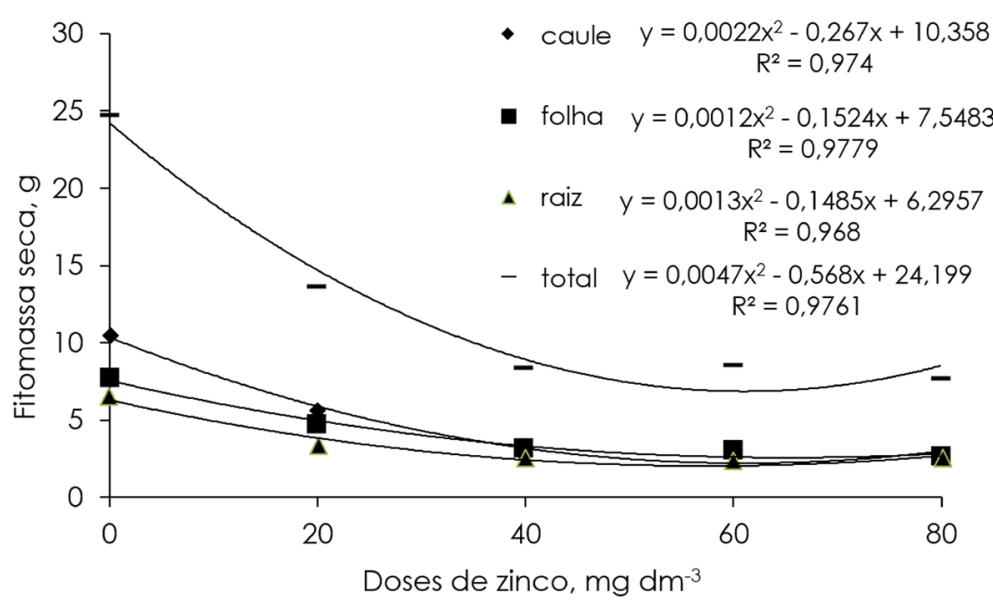

Figura 2. Fitomassa seca de caule, de folha, de raiz e fitomassa seca total das plantas de pinhão-manso em função das doses do zinco.

A redução do crescimento de girassol, de Vigna radiata (L.) Wilzeck e da aveia, devido ao $\mathrm{Cd}$, Cu e Zn foi observada por Gopal \& Khurana (2011), Manivasagaperumal et al. (2011) e Abranches et al. (2009), respectivamente. Esta redução na fitomassa, em excesso do metal pesado, pode ser devido à formação de baixo teor de proteína, resultando 
na inibição da fotossíntese, bem como dificultando a translocação de carboidratos (Manivasagaperumal et al., 2011).

Dentre as partes da planta, o caule, foi a mais atingida pelo efeito tóxico do Cu e/ou Zn, ou seja, com a aplicação da maior dose destes elementos no solo, reduziu a fitomassa seca do caule em torno de 80,37 e 74,88 \% para o Cu e o $\mathrm{Zn}$, respectivamente, em relação à testemunha. A diminuição da fitomassa seca das folhas e das raízes das plantas cultivadas com a maior dose de $\mathrm{Cu}$, em relação à testemunha, foi em torno de 68,78 e $61,53 \%$, respectivamente. No plantio com Zn, estas diminuições corresponderam a 66,06 e $61,38 \%$, respectivamente as folhas e as raízes. Em geral, considerando a redução da fitomassa seca total, as plantas submetidas às doses maiores de $\mathrm{Zn}$ foram mais tolerantes do que à aplicação de Cu no solo.

Segundo Kopittke \& Menzies (2006), a redução da massa seca das plantas não é devido a uma direta toxidez de Cu nas mesmas, mas sim, por causa de sua deficiência nutricional causada pelas lesões nas raízes provocadas pelos elevados teores de Cu no solo.

Em relação ao Zn, Malavolta et al. (1997) explicam que a redução na produção de matéria seca em planta submetidas a elevados teores deste elemento é devido ao acúmulo de tampões (plugs) contendo $\mathrm{Zn}$, no xilema das plantas, os quais dificultam a ascensão da seiva bruta.

Zeitouni et al. (2007), avaliando o desenvolvimento de plantas de mamona submetidas aos tratamentos com $\mathrm{Cu}(0$ a 40

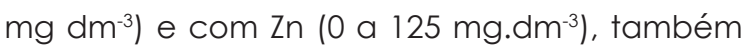
observaram diminuição na matéria seca das plantas com o aumento das doses dos metais aplicadas ao solo.

Os teores totais de Cu e Zn encontrados no solo, após a colheita das plantas, aumentaram em função das doses crescentes dos tratamentos e diferiram do valor inicial devido ao acúmulo dos metais pelas plantas (Figura 3 e 4 ), no entanto, pela análise de variância, somente os teores de $\mathrm{Zn}$ foram significativos a $1 \%$ de probabilidade (Tabela 2). O Zn como metal mais acumulado pelas plantas de pinhão-manso, conseqüentemente foi encontrado em menor teor no solo. O inverso ocorreu para o $\mathrm{Cu}$, por ter sido o metal menos acumulado nas plantas e encontrado em maiores teores no solo.

As doses crescentes de Cu não tiveram efeito significativo sobre o teor e o acúmulo deste elemento nas partes da planta; ao contrário, a aplicação de $Z n$ ao solo teve efeito significativo no teor do elemento nas partes da planta, caules, folhas e raízes, e no acúmulo deste elemento nos caules e nas folhas (Tabela 3).

Mesmo assim, quando comparados os dados de Cu com a testemunha, houve um aumento de 194, 23,43 e $367 \%$ do Cu no caule, folhas e raízes, respectivamente; já com a aplicação de $\mathrm{Zn}$ houve aumentos de 4284; 1272 e 1043 \% de Zn nas raízes, folhas e caule, respectivamente, quando comparados com a testemunha (Figura 5). Em geral, houve maiores

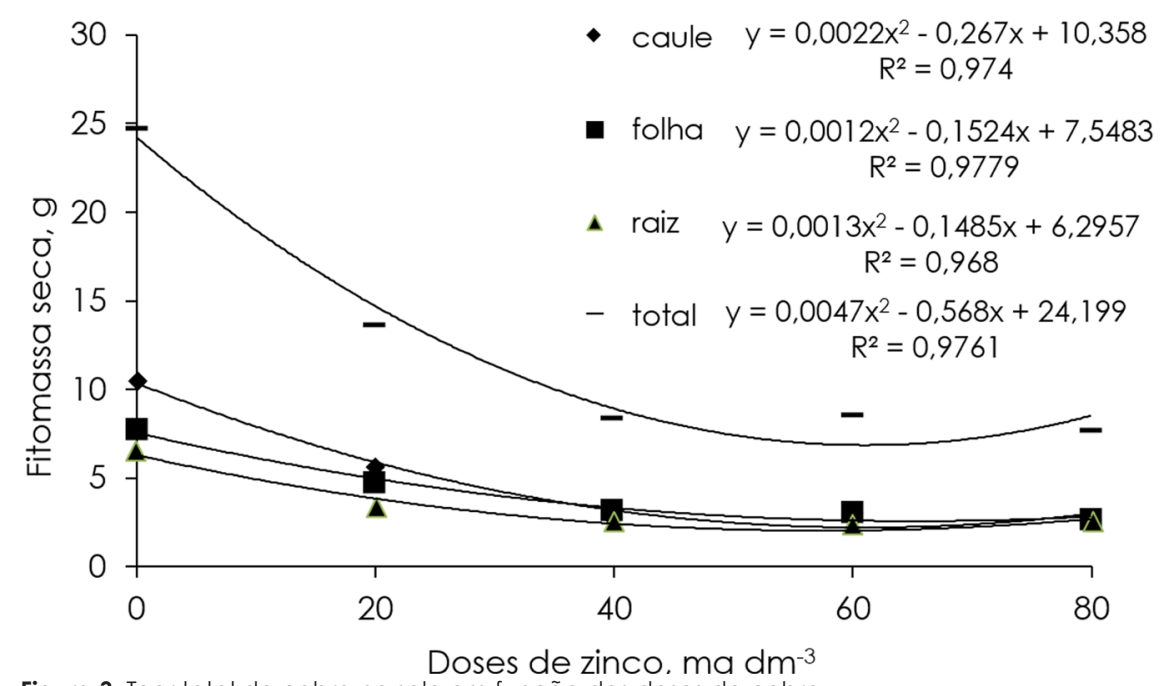

Figura 3. Teor total de cobre no solo em função das doses do cobre. 


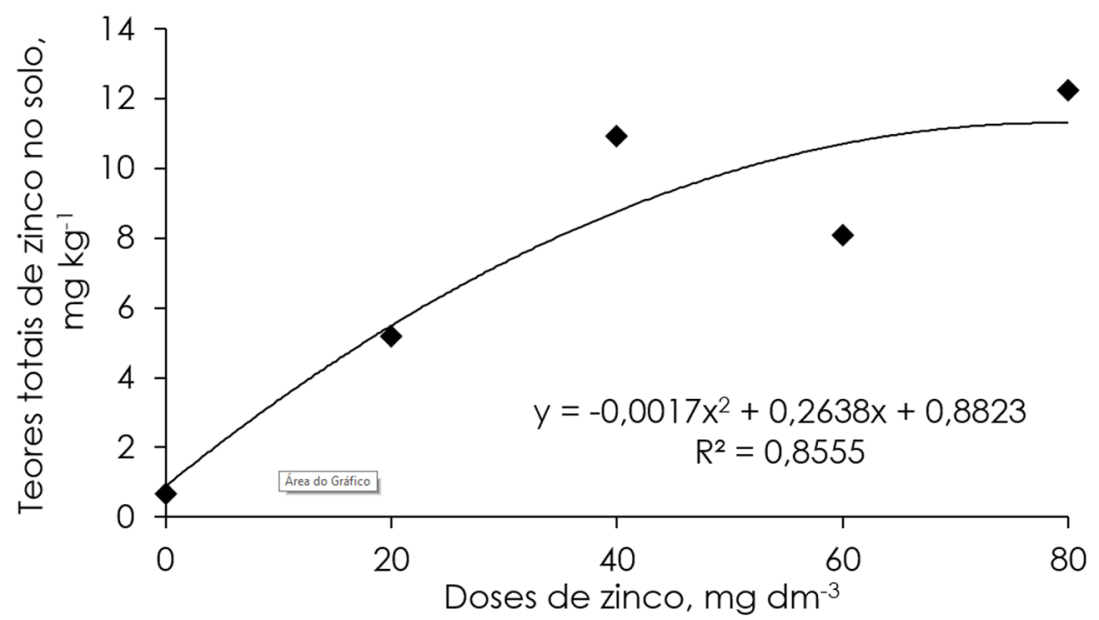

Figura 4. Teor total de cobre no solo em função das doses do zinco.

Tabela 2. Teores totais de Cu e Zn encontrados no solo.

\begin{tabular}{cccc}
\hline \multirow{2}{*}{ Fonte de Variação } & \multirow{2}{*}{ GL } & \multicolumn{2}{c}{ Quadrado médio - Teores no Solo } \\
\cline { 3 - 4 } & & Cu & Zn \\
\hline Tratamentos & 4 & $33429,566^{\text {ns }}$ & $64,95^{* *}$ \\
Resíduos & 10 & 8896,15 & 9,53 \\
CV \% & & 113,99 & 41,57 \\
\hline$; * * *$ Significativo no nivel de 5\% e 1\%, de probabilidade pelo teste F; respectivamente. ns = Não significativo.
\end{tabular}

Tabela 3. Resumo das análises de variância dos teores e acúmulo de cobre e zinco encontrados nas folhas, caule e raízes das plantas de pinhão-manso, em função das doses de cobre e zinco.

\begin{tabular}{|c|c|c|c|c|c|c|c|c|}
\hline \multirow{3}{*}{ Fonte de Variação } & \multirow{3}{*}{$G L$} & \multicolumn{7}{|c|}{ Quadrado médio } \\
\hline & & \multicolumn{3}{|c|}{ Teores } & \multicolumn{3}{|c|}{ Acúmulo } & \multirow[t]{2}{*}{ Acúmulo Tota } \\
\hline & & Caule & Folha & Raiz & Folha & Caule & Raiz & \\
\hline \multicolumn{9}{|l|}{ Cobre } \\
\hline Tratamentos & 4 & $2,20 \mathrm{~ns}$ & $4,13 \mathrm{~ns}$ & $146,11 \mathrm{~ns}$ & $0,00020 \mathrm{~ns}$ & $0,00002 \mathrm{~ns}$ & $0,00023 \mathrm{~ns}$ & $0,00039 \mathrm{~ns}$ \\
\hline Resíduos & 10 & 1,55 & 1,93 & 87,12 & 0,00026 & 0,00003 & 0,00015 & 0,00077 \\
\hline CV \% & & 56,29 & 37,71 & 73,80 & 103,95 & 65,60 & 43,02 & 52,71 \\
\hline \multicolumn{9}{|l|}{ Zinco } \\
\hline Tratamentos & 4 & $26393^{* *}$ & $22918^{*}$ & $2986068 *$ & $0,28^{*}$ & $0,53^{* *}$ & $25,45 \mathrm{~ns}$ & $36,27 \mathrm{~ns}$ \\
\hline Resíduos & 10 & 1167,65 & 3894,08 & 786742,87 & 0,05 & 0.08 & 9,81 & 10,95 \\
\hline CV\% & & 20,54 & 37,92 & 76,77 & 39,58 & 44.99 & 91,94 & 71,77 \\
\hline
\end{tabular}

teores destes elementos nas raízes, seguidos no caule e folha para Cu e na folha e caule para Zn. Este comportamento não foi observado por Santos et al. (2010) estudando a fitoextração de vários metais pesados por diversas espécies vegetais; neste ensaio houve maior acúmulo de Zn e Cu nos caules dos que nas raízes das plantas.

A concentração de Cu no caule, folhas e raízes estavam abaixo dos níveis críticos, ou seja, abaixo da variação de 20 a $100 \mathrm{mg} \mathrm{kg}^{-1}$. De forma semelhante, podem-se observar ainda os baixos valores de acúmulo do Cu pelo pinhãomanso. Resultados semelhantes para o Cu e Zn foram encontrados por Chaves et al. (2010).

A concentração de $\mathrm{Zn}$ no caule e nas folhas variou, mais ou menos, de 14-260 $\mathrm{mg} \mathrm{kg}^{-1}$ e nas raízes de $56-2480 \mathrm{mg} \mathrm{kg}^{-1}$. De acordo com Kabatia-Pendias \& Pendias (1992), os valores de 100 a $400 \mathrm{mg} \mathrm{kg}^{-1}$ são tóxicos e a planta é acumuladora de $\mathrm{Zn}$ se as plantas absorvem $1 \%$ do total presente $\mathrm{Zn}$ no solo, o que ocorreu neste caso.

A eficiência do pinhão-manso em remediar uma área contaminada com Cu e/ ou com Zn foi muito diferente levando-se em consideração o número de cultivos necessários para cada elemento (Tabela 4).

De acordo com este número, o pinhãomanso se mostrou mais eficiente em extrair $Z n$ do que Cu do solo, ou seja, para descontaminar o 
solo será necessário um maior número de cultivos em solos contaminados com o Cu. Conforme o número de cultivos para a descontaminação do solo a massa seca do pinhão-manso a ser produzida vai ser maior para Cu do que Zn.
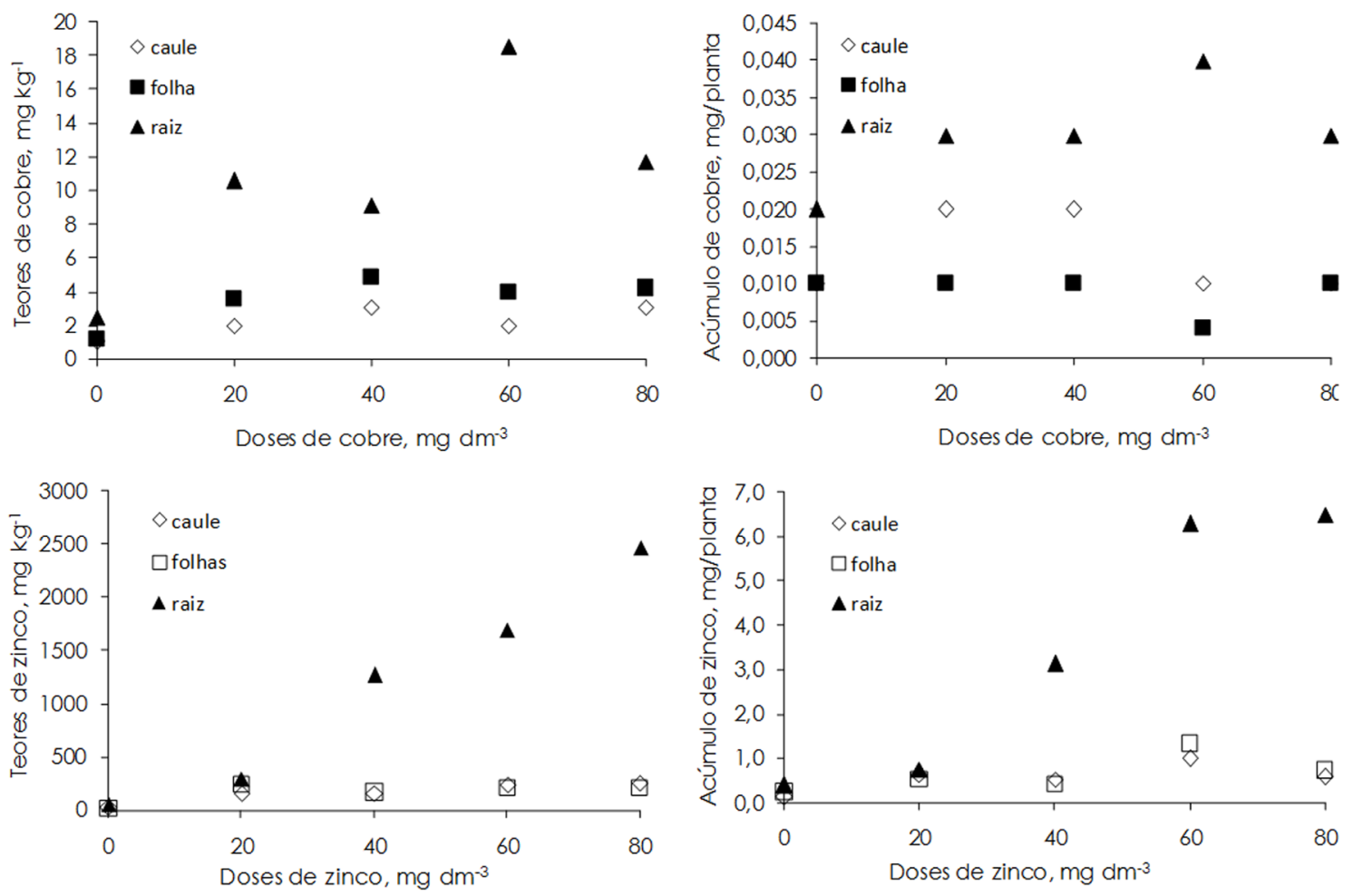

Figura 5. Teor e acúmulo do cobre e zinco nas partes das plantas em função das doses de cobre e de zinco, respectivamente.

Tabela 4. Matéria seca total na remediação e número de cultivos necessários para remediar o solo contaminado.

\begin{tabular}{|c|c|c|c|c|}
\hline \multirow{3}{*}{$\begin{array}{l}\text { Doses de Cu e } \\
\mathrm{Zn}\left(\mathrm{mg} \mathrm{dm}^{-3}\right)\end{array}$} & \multicolumn{4}{|c|}{ Remedição Total } \\
\hline & \multicolumn{2}{|l|}{$\mathrm{Cu}$} & \multicolumn{2}{|l|}{$\mathrm{Zn}$} \\
\hline & $\begin{array}{c}\text { Matéria seca produzida } \\
\text { (g vaso) }\end{array}$ & $\begin{array}{l}\text { Número de } \\
\text { cultivos }\end{array}$ & $\begin{array}{c}\text { Matéria seca produzida } \\
\text { (g vaso) }\end{array}$ & $\begin{array}{l}\text { Número } \\
\text { de cultivos }\end{array}$ \\
\hline 20 & 70309,03 & 5371,20 & 2973,37 & 212,40 \\
\hline 40 & 108514,6 & 9611,57 & 3095,96 & 369,45 \\
\hline 60 & 262265,1 & 40473,02 & 1913,79 & 223,83 \\
\hline 80 & 269279,9 & 38578,78 & 4149,15 & 533,31 \\
\hline
\end{tabular}

\section{Conclusões}

Para as condições apresentadas neste estudo, o pinhão-manso é mais eficiente em extrair zinco do que o cobre.

Para descontaminar o solo, será necessário um maior número de cultivos em solos contaminados com o cobre.

\section{Referências}

Abranches, J.L., Batista, G.S., Ramos, S.B., Prado, R.M. 2009. Resposta da aveia preta à aplicação de zinco em Latossolo Vermelho Distrófico. Revista Brasileria de Ciências Agrárias 4: 278-282.

Bouazizi, H., Jouili, H., Geitmann, A., Ferjani, E.E.I. 2010. Copper toxicity in expanding leaves of
Phaseolus vulgaris L.: antioxidantenzyme response and nutrient element uptake. Ecotoxicology and Environmental Safety 73: 1304-1308.

Chaves, L.H.G., Mesquita, E.F., Araujo, D.L., França, C.P. 2010. Crescimento, distribuição e acúmulo de cobre e zinco em plantas de pinhãomanso. Revista Ciência Agronômica 41: 167-176.

Chaves, L.H.G., Estrela, M.A., Souza, R.S. 2011. Effect on plant growth and heavy metal accumulation by sunflower. Journal of Phytology 3: 04-09.

Coscione, A.R., Berton, R.S. 2009. Barium extraction potential by mustard, sunflower and castor bean. Scientia Agricola 66: 59-63

Empresa Brasileira de Pesquisa Agropecuária- 
Embrapa. 2006. Sistema Brasileiro de Classificação de Solos. Embrapa Solos, Rio de Janeiro. 306p.

Ferreira, D.F. 2009. Estatística básica. 2. ed. UFLA, Lavras, $664 \mathrm{p}$.

Gabos, M.B., Abreu, C.A., Coscione, A.R. 2009. Edta assisted phytorremediation of a $\mathrm{Pb}$ contaminated soil: Metal leaching and uptake by jack beans. Scientia Agricola 66: 506-514.

Gopal, R., Khurana, N. 2011. Effect of heavy metal pollutants on sunflower. African Journal of Plant Science 5: 531-536.

Hansch, R., Mendel, R.R. 2009. Physiological functions of mineral micronutrients (CU, Zn, Mn, $\mathrm{Fe}, \mathrm{Ni}, \mathrm{Mo}, \mathrm{B}, \mathrm{Cl})$. Current Opinion in Plant Biology 12: 259-266.

Kabata-Pendias, A., Pendias, H. 1992. Trace elements in soils and plants. 2.ed. CRC Press, Boca Raton, $413 \mathrm{p}$.

Kopittke, P.M., Menzies, N.W. 2006. Effect of $\mathrm{Cu}$ toxicity on growth of cowpea (Vigna unguiculata). Plant and Soil 279: 287-296.

Lambert, L.F.M, Soares, R.P.S., Souza, S.C. 2012. O uso da fitorremediação para recuperação de solos contaminados por petróleo. III Congresso Brasileiro de Gestão Ambiental. http://www. ibeas.org.br/congresso/Trabalhos2012/XI-065. pdf $<$ Acesso em 06 de Out. 2014>.

Malavolta, E., Vitti, G.C., Oliveira, S.A. 1997. Avaliação do estado nutricional das plantas: principios e aplicacoes. Potafos, Piracicaba, 319 p.

Marques, T.C.L.L.S.M., Moreira, A.M.S., Siqueira, J.O. 2000. Crescimento e teor de metais de mudas de espécies arbóreas cultivadas em solo contaminado com metais pesados. Pesquisa Agropecuária Brasileira 35: 121-132.

Manivasagaperumal, R., Vijayarengan, P., Balamurugan, S., Thiyagarajan, G. 2011. Effect of copper on growth, dry matter yield and nutrient content of vigna radiata (I.) Wilczek. Journal of Phytology 3: 53-62.

Raskin, I., Kumar, P.B.A.N., Dushenkov, S., Salt, D.E. 1994. Bioconcentration of heavy metals by plants. Current Opinion Biotechnology 5: 285-290.

Santos, F.S., Magalhães, M.O.L., Mazur, N., Amaral Sobrinho, N.M.B. 2007. Chemical amendment and phytostabilization of an industrial residue contaminated with $\mathrm{Zn}$ and $\mathrm{Cd}$. Scientia Agricola 64: 506-512.

Santos, G.C.G., Rodella, A.A., Abreu, C.A., Coscione, A.R. 2010. Vegetable species for phytoextraction of boron, copper, lead, manganese and zinc from contaminated soil. Scientia Agricola 67: 713-719.

Sinhal, V.K. 2007. Phytotoxic and cytogenetic effects of $\mathrm{Zn}^{2+}$ and $\mathrm{Pb}^{2+}$ in Vicia faba. Pollution Research 26: 417-420.

Tandy, S., Bossart, K., Mueller, R., Ritschel, J., Hauser, L., Schulin, R., Nowack, B. 2004. Extraction of heavy metals from soils using biodegradable chelating agents. Environmental Science Technology 38: 937-944.

Tavares, S.R.L., Oliveira, S.S., Salgado, C.M. 2013. Avaliação de espécies vegetais na fitorremediação de solos contaminados por metais pesados. Holos 5: 80-97.

Upadhyay, R.K., Panda, S.K. 2009. Copperinduced growth inhibition, oxidative stress and ultrastructural alterations in freshly grown water lettuce (Pistia stratiotes L.). Comptes Rendus Biologies 332: 623-632.

Zeitouni, C.F., Berton, R.S., Abreu, C.A. 2007. Fitoextração de cádmio e zinco de um Latossolo vermelho-amarelo contaminado com metais pesados. Bragantia 66: 649-657. 